\title{
John B. Murphy (Chicago) †.
}

Von Prof. Dr. Mardill, Leitender Chirurg der Amerikanischen Ärzteexpedition. Festungslazarett in Graudenz.

Aus Amerika traf die traurige Nachricht ein, daB John $B$. I urphy in Chicago gestorben ist. Er erreichte ein Alter von 5) Jahren und arbeitete mit Eifer und Hingebung bis zu seinem 'oude. In Murphy verlieren wir einen der bedeutendsten Chirurgen nicht nur Amerikas, sondern überhaupt. Sein Ruhm drang weit über die Grenzen seines Vaterlandes hinaus. Murphy wurde geachtet und geehrt in allen Ländern der Welt. An den Fortschritten der Chirurgie nahm er regen Anteil. Zahlreiche wertvolle Arbeiten verdanken wir seinem Eifer und seinem Können. Jekannt sind seine Verdienste fuir die Entwicklung der Chirurgie des (iehirns, der Nerven, des Magen- und Darmkanals. Durch den ", Murphy' Knopf“ ist er geradezu populär geworden. Murphy war überhaupt ein Chirurgr ron glänzenden technischen Fähigkeiten.

Aber auch als I-ehrer leistete er Hervorragendes. Dienstags und Freitags hielt er klinische Vorträge vor einer Zuhörerschaft ron 200. 300 Chirurgen. Seine klaren Worte, seine anschauliche Analyse der Krankheitsfälle and sein Enthusiasmus begeisterte geradezu seine Zuhörer.

In der letzten Zeit beschäftigte sich Murphy mit der Knochenund Gelenkschirurgie und widmete ihr seine ganze Arbeitskraft. In der Wiederherstellung der Bewerglichkeit versteifter IIüft- und Kiniegelenke leistete er Erstaunliches. Scine Patienten gingen so rorzüglich, daß man das kranke von dem gesunden Bein nicht unterscheiden konnte. Die "Murphy-Artroplastics" kommen geracle jetzt im Weltkriege zu ihrem vollen Recht, und darum will ich mit einigen Worten auf das Verfahren eingehen.

Die Operation besteht darin, daß man das versteifte Gelenk freilegt und die Knochenenden so modelliert, daß sie ungefähr 
den normalen Formen gleichkommen. Dann werden autoplastische, gut genährte große Lappen von Fett- oder Fasciengewebe dazwischen gelegt. Nur wo genug Haut und Gewebe unter derselben vorhanden ist, hat die Operation Aussicht auf Erfolg. Leider trifft man gerade bei Kriegsverletzungen zu häufig auf ausgedehnte Narben. Bei der Kniegelenksoperation drehte Murphy die Patella ganz herum, um die präpatellaren Schleimbeutel für den vorderen Teil des neuen Gelenkes zu benutzen. Sehr sorgfältige Blutstillung ermöglichte, die Wünde ganz zu schließen. Drains kamen nicht zur Anweidung. Mit aktiven und passiven Bewegungen wurde bald begonnen.

Mit diesen Gelenksmobilisationen erzielte Murphy, wie gesagt, vorzügliche Resultate, selbst bei ganz verödeten Gelenken; die Technik will jedoch gelernt und geübt sein.

Murphy war in der Technik äußerst gewissenhaft. Kam er ron seiner einmonatlichen Ferienerholung wieder zurück an die Klinik, so übte er die Operation erst an der Leiche, bevor er sie an Lebenden ausführte. An diessr großen Sorgfalt liegt es wohl, daß dic Gelenksoperationen so vorzügliche Resultate ergaben. Ijese Operationen sind nicht für jedermann, sie erfordern gründliche Einübung an der Leiche und ein ganz besonderes Studium, um alle Einzelheiten des Verfahrens zu beherrschen. Wer keine Übung hat, wird selten etwas Gutes erreichen; ein solcher kann die so segensreiche Operation nur in Mißkredit bringen.

Wic ich höre, besteht der Plan, zum Gedächtnis an Dr. Murphy eine Stiftung von $2^{1 / 2}$ Millionen Mark zur Errichtung eines Gebäudes für das „American College of Surgeons" oder irgendeinen anderen wissenschaftlichen $Z$ weck zu bestimmen.

Zum Schluß noch einige Daten aus dem Lexikon: „Who's who in America".

Murphy, John Benjamin, Chirurg; geboren in Appleton, Wisconsin, am 21. Dez. I 857 , absolvierte die Schule allda, Juni 1876; promovierte 1879 zum Doktor der Medizin am .,Rush Medical College" zu Chicago (L L. D. der Universität Illinois, I905; M. Sc. der Universität Sheffield, England, I908); praktizierte in Chicago von $1879-1882$; studierte in Deutschland I882-I884; nahm die Praxis in Chicago wieder auf; Chef der Abt. für Chir. und klin. Chir. in der Northwestern U. Med. School, 
und Prof. d. klin. Chir. an der „Chicago Post-Grad. Med. School“, seit 1895; beratender Chirurg der Cook Co. und der Alexians Brothers Hospitals; leitender Chirurg des Mercy Spitals, Chirurg am West Side Hospital; crhielt die Laetar-Medaille der Notre Dame U. in 1902. - Fellow der "American Surgical Assoc.", lebensl. Mitgl. der Deutschen Gesellsch. f. Chir., Berlin, und der Société Chirurgicale, Paris; Mitgl. d. Amer. Assoc. of Obstetricians and Gynecologists, Präsident d. Intern. Med. Congr., A. M. A., und Mitglied der folgenden Gesellschaften: Ill. State Med. Soc.; Miss. Valley Med. Assoc.; Chicago Med., Surg., Gynecol. and Pathol. socs.; Chicago Soc. of Internal Medicine; Medico-Legal Soc.; Physicians' Club. 